\title{
Práticas linguageiras e ethos discursivo: vozes de sujeitos "que falam" sobre o trabalho
}

\author{
Language practices and discursive ethos: voices of subjects "who speak" about the work
}

\author{
Ernani Cesar de Freitas \\ Itatiane Chiaradia \\ Débora Facin
}

Universidade de Passo Fundo - Passo Fundo - Rio Grande do Sul - Brasil

\begin{abstract}
Resumo: Este estudo teve por objetivo apresentar uma interface entre a temática Linguagem e Trabalho (SCHWARTZ, 2010; TRINQUET, 2010; NOUROUDINE, 2002) e a Teoria enunciativo-discursiva (MAINGUENEAU, 1997, 2008a, 2008b, 2008c, 2008d, 2010, 2011a, 2011b) como possibilidade de se analisar a cenografia e o ethos construídos a partir de dizeres de pessoas que se encontram em situações de trabalho, especificamente de sujeitos participantes de uma associação de catadores de material reciclável, no município de Passo Fundo, RS, também verificando o Regimento e o Estatuto. Este trabalho caracteriza-se como descritivo, bibliográfico e documental, com análise qualitativa. A pesquisa revelou que, se a ideia de ethos é sociodiscursiva e apresenta um comportamento socialmente avaliado, a imagem de si - relações hierárquicas, submissão e valores que circunscrevem o ambiente de trabalho - depreende-se através de enunciados, que constituem e constroem a cenografia discursiva, sobretudo, valores sobre a atividade caracterizados por manifestações de poder e o uso de si por outro.
\end{abstract}

Palavras-chave: Cenografia; Ethos; Ergologia; Linguagem sobre trabalho

\begin{abstract}
The aim of this study has been to present an interface between the theme Language and Work (SCHWARTZ, 2010; TRINQUET, 2010; NOUROUDINE, 2002) and the enunciative discursive Theory (MAINGUENEAU, 1997, 2008a, 2008b, 2008c, 2008d, 2010, 2011a, $2011 b$ ) as a possibility to analyze the scenery and the ethos which have been gathered from people's talks once in work situations - specifically of people who work in an association of people who collect recyclable material - in Passo Fundo city, south Brazil. This study was done based upon a literature review; it is a qualitative, descriptive and bibliographical one. This research has shown that, if the ethos concept is socio-discursive and presents a behavior that is socially evaluated, the one self's image - hierarchical relationships, submission and values which circumscribe the work environment - is understood through utterances which build the discursive scenery and, most importantly, values about this one activity that have the characteristics of power manifestations and the use of one self by the other self.
\end{abstract}

Keywords: Scenery; Ethos; Ergology; Work language

\section{Introdução}

O tema deste artigo insere-se na temática linguagem e trabalho, mais precisamente sobre o entendimento que indivíduos partícipes de uma associação de catadores de materiais recicláveis, em um bairro da cidade de Passo Fundo, RS, manifestam acerca desse meio laboral.

Denominado como Associação Amigos do Meio Ambiente (AAMA), trata-se de um projeto sem fins lucrativos e apresenta como objetivo principal a promoção integral do ser humano mediante o trabalho realizado por esses indivíduos.

Em se tratando de um ambiente de interação social, nossa proposta foi promover um estudo interdisciplinar aproximando a ergologia e a enunciação de cunho sociodiscursivo, como alicerce para analisar a cenografia e o ethos construídos a partir de dizeres de pessoas que se encontram em situações de trabalho, especificamente 
de sujeitos participantes de uma associação de catadores de material reciclável, no município de Passo Fundo, RS.

A problemática que nos induziu a realizar este estudo consiste na seguinte questão: a cenografia e o ethos discursivo possibilitam revelar uma representação sociocultural da associação construída pelos indivíduos que dela participam? Com o propósito de respondermos a esse questionamento, a seguinte hipótese foi elaborada: por meio do estudo da cenografia e do ethos, é possível tornar notórios os saberes sobre a atividade expressa pelos atores do trabalho. Isso porque a análise de discurso, sob as noções de cenografia e ethos discursivo, possibilita ao analista a delimitação e a construção de um roteiro metodológico mais claro e preciso.

A teoria de Maingueneau (1997, 2008a, 2008b, 2008c, 2008d, 2010, 2011a, 2011b), para nós, é produtiva, pois viabiliza, ao mesmo tempo, olhar para o plano enunciativo e para o discursivo. Construir uma cena não é nem abreviar o enunciado a leituras gramaticais, nem afastá-lo a instâncias totalmente pragmáticas. Para o analista, estudar a cenografia e o ethos é observar tanto os sinais do enunciador deixados no discurso (na, pela e sobre linguagem) quanto as trocas interdiscursivas que definem cada posicionamento.

Foi sob esse enfoque que elaboramos nosso roteiro metodológico: o estudo caracteriza-se como descritivobibliográfico e documental, com estudo de caso e abordagem qualitativa. A coleta de dados realizou-se mediante a aplicação de entrevista semiestruturada e da técnica observação sistemática, além da pesquisa documental.

Estruturalmente, o texto está assim organizado: na primeira seção, fazemos uma abordagem a respeito da aproximação linguagem e trabalho a fim de esclarecer alguns conceitos que norteiam a experiência humana na atividade de catadoras de materiais recicláveis. Em seguida, abordamos os conceitos de cenografia e ethos discursivo para analisar os discursos (depoimentos) selecionados e os documentos que regem o funcionamento da Associação - Estatuto e Regimento. A metodologia e a análise apresentam os dispositivos de avaliação e os resultados encontrados; por fim, as considerações finais sugerem algumas possibilidades que a interlocução entre as disciplinas envolvidas neste texto promove no espectro dos estudos acadêmicos.

\section{Experiência de trabalho e linguagem: uma relação necessária}

Reportando-nos aos anos 1980, quando pensar a relação homem e trabalho significava visualizar a atividade humana operacionalizada por ritmos mecânicos. Era o trabalho operário que caracterizava o sistema taylorista, marcado por prescrições de objetivos e procedimentos, que distanciava do ambiente laboral qualquer manifestação de competência singular do indivíduo.

No entanto, essa forma de trabalhar entra em declínio e cede espaço "às novas formas de trabalhar" (SCHWARTZ, 2010a). Se num período anterior o trabalho era tido como o seguimento de leis que norteavam o que e como o indivíduo devia operar, na atividade real do trabalho "atualiza-se uma interpretação individual dessas normas, de acordo com a história de vida, da subjetividade de cada trabalhador e do coletivo ao qual ele pertence" (FREITAS; CHIARADIA, 2012, p. 94).

Nesse sentido, as investigações acerca do trabalho ganham novos horizontes, visto que é inviável abreviar a atividade num mero cumprimento de normas. Interdisciplinarmente, Schwartz (2010a) investe em uma teoria que procura elucidar novas maneiras de melhor intervir sobre as relações de trabalho: a ergologia, definida como "aprendizagem permanente dos debates de normas e de valores que renovam indefinidamente a atividade". (SCHWARTZ, 2010a, p. 30).

É nesse repensar a atividade que o diálogo com a linguagem soa não só necessário como produtivo. Faïta (2002, p. 47) ressalta que a linguagem configura-se como um "elemento essencial na construção da ação e da significação, na afirmação das identidades profissionais, no planejamento, na coordenação, na negociação das atividades e das tomadas de decisão".

Ante essa perspectiva, a teoria de Maingueneau sobre cenografia e ethos pode ocupar um lugar especial na área da ergologia, pois, se o trabalho está intimamente ligado ao universo social, a propriedade enunciativa do ethos e sua relação com o gênero do discurso orientam para um "processo interativo de influência sobre o outro". (MAINGUENEAU, 2011b, p. 17). Portanto, aproximar a linguagem e o trabalho é, ao mesmo tempo, uma ação individual e coletiva e, "por meio dessa relação com o outro, tudo isso remete profundamente a uma forma de construção de si-mesmo que traz toda espécie de desafios e de dimensões." (SCHWARTZ, 2010b, p. 192).

Sob o ponto de vista da filosofia, Nouroudine (2002, p.17) aponta a relação linguagem e trabalho sob três modalidades: a "linguagem sobre o trabalho", a "linguagem no trabalho" e a "linguagem como trabalho". Para este artigo, detemo-nos especificamente à "linguagem sobre o trabalho". A respeito dessa categoria, esse autor destaca que ela é necessária por exigências do grupo ou da empresa a fim de avaliar o trabalho, comentá-lo, lembrá-lo. No entanto, a necessidade de se falar sobre o trabalho implica questionar acerca de "quem fala?", "de onde ele/ela fala?", "quando ele/ela fala?" com o propósito de entender "onde se situa o campo de validade e de pertinência da "linguagem sobre o trabalho"" (NOUROUDINE, 2002, p. 26). 
No que se refere à atividade sobre o trabalho, Nouroudine (2002) alerta para a complexidade que envolve a exploração dessa modalidade. Isso porque falar a respeito da atividade requer a consideração das singularidades que envolvem as práticas linguageiras. Assim, é inviável - por parte do pesquisador - qualquer tentativa de neutralização da linguagem no momento da interpretação das informações, "pois o que está em jogo na tentativa de descrição e interpretação da experiência do outro não provém unicamente do método utilizado, mas também dos valores manifestados" (NOUROUDINE, 2002, p. 28).

Se a atividade humana "é definida pela dimensão simbólica" (TEIXEIRA, 2012, p. 38), a linguagem tem um valor ímpar - sobremaneira quando recepcionada por uma teoria enunciativo-discursiva. Conforme Schwartz (2010c, p.139), a linguagem é "lugar e elemento de fabricação dos conceitos que enquadram as atividades de trabalho em todas as suas dimensões [...]".

Do ponto de vista da ergologia, para estudar uma situação de trabalho, é imprescindível reconhecer as normas antecedentes, porque são os saberes produzidos que organizam a atividade. Mais do que isso: permitem reorganizá-la, ressignificá-la em consonância com o coletivo. No contexto da atividade, "é impossível repetir uma tarefa, uma prescrição, uma vez que as renormalizações são permanentes" (DI FANTI, 2012, p.318).

Schwartz (2010a), quanto ao conceito de atividade, define quatro proposições especificamente ergológicas: "a distância entre o prescrito e o real", "o conteúdo da distância é sempre parcialmente ressingularizado", a "distância remete à atividade do corpo-si", "a distância remete a um debate sobre os valores".

$\mathrm{O}$ autor salienta que a distância entre o prescrito (pensado antecipadamente) e o real (trabalho efetivo) é universal e caracteriza o ponto de partida da Ergonomia, visto que sempre haverá essa distância entre o que é teorizado sobre o trabalho e a realização desse trabalho. E nunca saberemos o ponto-chave dessa distância, o que é perfeitamente coerente. Há, porém, de se reconhecer nessa distância a atividade do corposi, que "assinala a dificuldade de pensar o sujeito da atividade, porque não é nem o sujeito perfeitamente consciente, nem o sujeito perfeitamente inconsciente, enfim esta entidade atravessa nisso tudo" (SCHWARTZ, 2010a, p. 44).

Compreender o sujeito do trabalho implica compreender os valores que circunscrevem esse indivíduo. Se hoje não nos deparamos (ou pelo menos não deveríamos nos deparar) com modelos tayloristas de trabalho, a atividade humana passa a se configurar ante essas características pensadas por Schwartz (2010a, p.46): existe sempre uma distância entre o prescrito e o real a qual é sempre ressignificada; essa distância "é uma entidade simultaneamente alma e corpo"; o trabalho é e sempre será constituído pelo encontro de valores.

Trinquet (2010, p. 96) nos alerta sobre a distinção entre trabalho e atividade e, além disso, a dificuldade de reconhecer a diferença:

A dificuldade metodológica reside no fato de que, ao falar da atividade do assalariado, introduzimos-nos, infiltramos-nos em sua intimidade, em sua atividade interior, que é muito pessoal. Isso quer dizer que, espontaneamente, ele nos fala de sua tarefa, de seu posto de trabalho; o resultado - material ou intelectual - que é esperado; os procedimentos que deve seguir e colocar em prática; os materiais que utiliza; etc. Isso não lhe traz nenhum problema já que ele não está pessoalmente implicado. Essa situação é geral e válida para todos.

É notório que o interesse pelo trabalho limita-se à ordem do prescrito. É tão somente o operacional que o sujeito visualiza e nada mais. Freitas (2011, p. 108) salienta que o trabalho prescrito "[...] corresponde aos documentos que instruem, ensinam, aconselham etc. o trabalho a ser realizado. Instituições ou empresas os produzem anteriormente à realização efetiva do trabalho para representar o que deve (ou não) e como deve ser feito".

De acordo com Faïta (2002, p.51), a fala no trabalho e a fala sobre o trabalho "são marcadas, tanto uma quanto a outra, pela relação que mantêm com a ação [...] a competência e os saberes dos sujeitos nos parecem incorporados simultaneamente às maneiras de dizer e às maneiras de agir orientadas a um objetivo comum". Essas práticas linguageiras, por vezes, se aproximam, se distanciam e se entrelaçam, permitindo que o conhecimento seja disponibilizado em favor da realização, ou não, do trabalho.

O sujeito da ergologia sempre reconfigura o trabalho, as normas de acordo com as necessidades impressas no momento. Segundo Souza-e-Silva (2002, p. 72), “[...] o retrabalho permanente das normas supõe também um retrabalho dos discursos", o que remete ao entrelaçamento da ergologia e da linguagem, e, nesse sentido, o sujeito da ação necessita ser considerado em relação ao seu discurso.

Com o propósito de analisar a linguagem em situações de trabalho, especificamente a imagem construída por pessoas incluídas nesse meio, o texto da próxima seção dispõe de algumas considerações sobre a forma - por nós eleita - de olhar para a atividade: pela cenografia e pelo ethos. 


\section{Sobre cenografia e ethos: um modo de se analisar discursos}

Possenti (1993, p.29), quando de seu Esboço de uma epistemologia da análise do discurso, assinala duas instâncias teóricas: por uma lado, os autores que recepcionam a análise discursiva tão somente pela perspectiva história e ideológica apresentam-se "exigindo demais", visto que nem sempre um enunciado pode ser analisado apenas por esse viés; por outro lado, os autores que fazem parte das teorias linguísticas "exigem de menos", pois, para a análise de alguns enunciados, a linguística por si não é suficiente para interpretar certos fenômenos. Portanto, o quadro epistemológico da análise de discurso deveria englobar: "uma teoria linguística; uma teoria auxiliar (relativa ao campo 'não linguístico' mais pertinente para a análise de um determinado [tipo de] discurso)" (POSSENTI, 1993, p. 30).

Sobre a problemática que impera a disciplina "análise do discurso", conforme Maingueneau (2008d, p. 143), o interesse é

apreender o discurso como entrecruzamento de um texto e de um lugar social, quer dizer que seu objeto não é nem a organização social nem a situação de comunicação, mas aquilo que os une através de um dispositivo de enunciação específico que provém, ao mesmo tempo, do verbal e do institucional.

Nesse particular, a postura teórica de Maingueneau (2008d) acerca da análise de discurso - e por nós adotada - não é nem pensar as palavras independentemente do campo discursivo que as autoriza, nem pensar os lugares de modo autônomo às coerções de um gênero específico. Maingueneau (2008a) inscreve sua forma de fazer análise do discurso à semântica global, ou seja, o discurso é apreendido na multiplicidade de seus planos. Acrescentese, em estudos posteriores do linguista francês, a noção de cenografia e de ethos discursivo, categorias estas que orientam teórica e metodologicamente a análise do nosso corpus de pesquisa. Isso porque os estudos realizados por Maingueneau a respeito da semântica global, cenografia e ethos discursivo possibilitam uma orientação, conforme assim entendemos, mais precisa em termos de metodologia. Para nós, há necessidade de investigar os reflexos da linguagem em situações de trabalho sob orientação de um quadro teórico-metodológico que proporcione algumas categorias essenciais para análise. É por meio dessas categorias - definidas na sequência - que analisamos a representação que os sujeitos inscritos em uma situação enunciativa revelam sobre a atividade.

Além disso, acreditamos que a cenografia é a categoria principal por dialogar com os planos constitutivos da semântica global; a encenação de um discurso nada mais é do que as pistas deixadas por um enunciador que toma a palavra - referimo-nos aqui não apenas ao discurso oral, mas ao escrito - e a partir dela o legitima e valida seu dizer.

A cena de enunciação é seguidamente empregada como "situação de comunicação"; trata-se de um "espaço instituído, definido pelo gênero de discurso, mas também sobre a dimensão construtiva do discurso, que se 'coloca em cena', instaura seu próprio espaço de enunciação" (CHARAUDEAU; MAINGUENEAU, 2008, p. 95, grifo do autor). O sentido de "-grafia", neste particular, compreende este círculo: o discurso implica um enunciador e um coenunciador, espaço e tempo da enunciação que valida a própria instância e permite sua sobrevivência.

Conforme Maingueneau (2011a, p. 85), "um texto não é um conjunto de signos inertes, mas o rastro deixado por um discurso em que a fala é encenada." A cena de enunciação compreende três cenas, quais sejam: a englobante, a genérica e a cenografia. A cena englobante refere-se ao tipo de discurso, que pode ser político, religioso, administrativo etc.; os locutores, por sua vez, "só interagem nas cenas englobantes através de gêneros de discurso específicos, de sistema de normas: pode-se então falar de "cena genérica" (MAINGUENEAU, 2010, p.206, grifo do autor). A cenografia é construída pelo próprio texto e não diz respeito a um espaço físico, como se o enunciador pertencesse a um ambiente "emoldurado", mas sim a um espaço que é validado por meio da própria enunciação. Desse modo, a cenografia implica um processo de enlaçamento paradoxal entre as cenas, ou seja, a fala supõe uma situação de enunciação que é validada à medida que a própria enunciação se consolida (MAINGUENEAU, 2011a).

Faïta (2002) insiste na ideia de que, contrariamente ao senso comum, "dizer não é algo simples", pois não se trata de algo mecânico. Dizer/comunicar implica compreender. Sendo assim, o processo de compreensão de enunciados requer que se considere, inclusive, o papel do outro na situação de comunicação. Ressaltamos, nesse particular, o que Maingueneau (2008a) considerou como um dos planos da semântica global: o estatuto de enunciador e de destinatário.

"Cada discurso define o estatuto que o enunciador deve se atribuir e o que deve atribuir a seu destinatário para legitimar seu dizer" (MAINGUENEAU, 2008a, p. 87, grifo do autor). Em termos de discurso, tanto o enunciador quanto o destinatário dispõem de um lugar e, nesse espaço, o enunciador projeta uma imagem de si no discurso a partir da qual o legitima. As categorias de enunciador e de destinatário correspondem às pessoas que fazem parte da situação de comunicação. Desse modo, tanto o enunciador quanto o destinatário estão 
relacionados à cena da enunciação, os quais demarcam seu posicionamento e validam o dizer. Em se tratando de cenografia, os actantes da enunciação têm papel fundamental, pois, além de converterem a língua em discurso, como assevera Benveniste (2006), criam diferentes efeitos de sentido, de identidade.

Na obra Gênese dos discursos, Maingueneau (2008a) não aborda explicitamente sobre a imagem de si, mas trata de um estatuto de enunciador e de destinatário e também do modo de enunciação, planos estes que, de acordo com nosso entendimento, são noções primeiras relativas ao ethos discursivo ${ }^{1}$. É a semântica global que explica a dêixis enunciativa, a qual legitima a cena e a cronologia e autoriza sua própria enunciação.

A concepção discursiva de ethos, neste estudo, advém da semântica global e é aplicada a discursos que não necessariamente apresentem sequências argumentativas. É o posicionamento do enunciador que definirá seu modo de enunciação, ou melhor, seu ethos. Nesse particular, não podemos reduzir o ethos, na análise do discurso, a um mecanismo de persuasão; ele é intrínseco à cena de enunciação. "O texto escrito possui, mesmo quando o denega, um tom que dá autoridade ao que é dito" (MAINGUENEAU, 2011a, p.98, grifo do autor), isto é, uma instância subjetiva que compreende o papel de fiador do discurso (MAINGUENEAU, 2011b). "Essa instância subjetiva que atesta o que é dito não está relacionada a um autor efetivo; trata-se de uma representação que o leitor faz do enunciador a partir de índices textuais de diversas ordens - léxico, estrutura sintática etc." (MUSSALIM, 2011, p. 71). Tais índices permitem retomar o que Maingueneau (2008a) denominou como sistema de restrições semânticas globais. "A semântica global de um discurso também define um ethos característico (doce, duro, irônico...) e, em decorrência, em boa medida, seu léxico, que, por sua vez, é um dos elementos que dão concretude ao ethos" (POSSENTI, 2011, p. 150).

A imagem abstrata construída no e pelo discurso pelo fiador - constitui-se de duas propriedades: caráter e corporalidade. "O 'caráter' corresponde a um feixe de traços psicológicos. Quanto à 'corporalidade', ela é associada a uma compleição física e a uma forma de se vestir. Além disso, o ethos implica uma forma de mover-se no espaço social, uma disciplina tácita do corpo, apreendida por meio de um comportamento" (MAINGUENEAU, 2008c, p. 65).

Maingueneau (2011b) faz um desdobramento do conceito de ethos; este resulta da interação de ethos pré-discursivo ou ethos prévio; ethos discursivo (ethos mostrado e ethos dito); ethos efetivo. O ethos prédiscursivo ou prévio corresponde à imagem que o

\footnotetext{
1 A noção de ethos foi tratada, mais especificamente, por Maingueneau (1997, p.45), no livro Novas tendências em análise do discurso.
}

coenunciador faz do enunciador antes mesmo que este fale; isso é possível visto que o ethos está intimamente relacionado à cenografia e, consequentemente, ao gênero discursivo. A diferença entre o ethos dito e o ethos mostrado - ethos discursivo - está na forma como o enunciador constrói sua própria enunciação. No caso do ethos dito, "trata-se das diferentes formas que o fiador utiliza para evocar, indiretamente, o ethos do discurso que ele materializa" (SILVA, 2006, p. 183). O ethos mostrado diz respeito a todas as marcas - semântica global - que particularizam o modo de ser do enunciador. "A distinção entre ethos dito e mostrado se inscreve nos extremos de uma linha contínua, uma vez que é impossível definir uma fronteira nítida entre o 'dito' sugerido e o puramente 'mostrado' pela enunciação" (MAINGUENEAU, 2011b, p. 18, grifo do autor). Quanto ao ethos efetivo, este é resultado da interação das diversas instâncias (entre ethos pré-discursivo e discursivo, entre ethos dito e mostrado).

Ethos mais cenografia constitui um processo de enlaçamento. "São os conteúdos desenvolvidos pelo discurso que permitem especificar e validar o ethos, bem como sua cenografia, por meio dos quais esses conteúdos surgem" (MAINGUENEAU, 2008c, p. 71). Quando mencionamos o processo de enlaçamento e retomando a noção de cenografia com a metáfora do cenário, fica claro que o ethos discursivo é revelado à medida que todos os planos são avaliados em determinado discurso. Estatuto de enunciador, coenunciador, dêixis discursiva e a própria escolha lexical são propriedades intrínsecas à construção da "imagem de si". O coenunciador, por exemplo, não é apenas um mero receptor de ideias, mas é "alguém que tem acesso ao 'dito' através de uma 'maneira de dizer' que está enraizada em uma 'maneira de ser', o imaginário de um vivido" (MAINGUENEAU, 1997, p. 49).

Desde os fundamentos que definem a semântica global, cenografia até o ethos discursivo, eleger algumas categorias - aqui entendidas como sinais, pistas deixadas pelo enunciador - é válido a uma pesquisa de caráter enunciativo-discursivo e qualitativo. Desse modo, para que possamos analisar a cenografia e o ethos que se depreende dos corpora de estudo, não nos parece pertinente a quantificação e armazenamento de dados, mas sim a atenção a detalhes que singularizam o olhar do analista. É disso que trataremos na próxima seção: a metodologia e a análise.

\section{Metodologia e análise}

\subsection{Sobre os corpora de pesquisa: breve contextualização}

Primeiramente, esclarecemos que a constituição dos corpora de estudo é resultado de uma pesquisa 
institucional vinculada ao Programa de Pós-graduação em Letras da Universidade de Passo Fundo. Esses corpora têm como objeto de estudo a Associação Amigos do Meio Ambiente (AAMA), fundada em 4 de dezembro de 2008, que possui como membros catadores de materiais recicláveis e é amparada por um representante da Igreja Católica, além de voluntários representantes da sociedade local.

$\mathrm{Na}$ pesquisa de campo, em sua totalidade, foram entrevistadas quatro pessoas de um total de treze (a maioria analfabeta). Para este artigo, não contemplamos todo o roteiro de entrevista, e sim elegemos uma questão especificamente que pareceu mais representativa ao objetivo de estudo. Selecionamos duas falas acerca do que a AAMA representa na vida dessas trabalhadoras (todas do sexo feminino) e o que significa trabalhar em equipe. Em contraponto com a fala de duas associadas, também julgamos pertinente abordar a fala do coordenador do grupo sobre a maneira como ele trabalha com a equipe e sua função como coordenador na Associação e, também, um recorte do Regimento Interno da AAMA e do Estatuto da Associação.

Essa escolha se pauta, sobretudo, pela tensão e complexidade configuradas no uso de si por si e pelos outros, ou melhor, conforme Schwartz (2010b, p. 195), pela necessidade de "negociação" entre os sujeitos partícipes da atividade, visto que a ideia ergológica de trabalho afasta qualquer noção puramente prescritiva. Antes de tudo, o exercício profissional é um fazer singular, é uma atividade enunciativa.

É nesse aspecto que a interface entre os saberes da teoria enunciativo-discursiva da linguagem (Dominique Maingueneau) e da concepção ergológica (Yves Schwartz) parece frutífera. Se o agenciamento de operações predefinidas não são garantias de concretude no trabalho - remetendo ao modelo taylorista -, a subjetividade ganha espaço à medida que começa a aparecer no ambiente de trabalho um indivíduo que se expressa.

Esta pesquisa caracteriza-se como exploratóriodescritiva. Isso porque o estudo parte de um levantamento bibliográfico para proceder à descrição e análise qualitativa dos corpora selecionados. Foi necessária também a pesquisa documental, visto que analisamos o Estatuto e o Regimento Interno para melhor compreender o funcionamento histórico-social da Associação.

\subsection{Procedimentos metodológicos}

No sentido de que os objetivos possam ser concretizados, alguns procedimentos metodológicos foram delineados, com destaque a algumas categorias teóricas na análise. No que diz respeito à perspectiva ergológica: consideramos o trabalho sob o viés da ati- vidade, a linguagem como atividade, o uso de si por si e pelos outros. Quanto à concepção enunciativo-discursiva da linguagem no trabalho: damos ênfase ao estatuto do enunciador e do coenunciador, à dêixis enunciativa, ao modo de enunciação, à cenografia e ethos discursivo.

A exploração desses conceitos permite conceber o discurso dotado de dinamismo, de movimentação. Os indícios da semântica global viabilizam não apenas analisar as ideias expostas no discurso, mas também como estas funcionam e se relacionam com o mundo do trabalho.

É a partir da constituição da cena enunciativa que se depreende o ethos discursivo, o qual será identificado considerando-se os estereótipos que circunscrevem o "mundo ético" do trabalho, o ethos pré-discursivo, o ethos dito e o ethos mostrado.

\subsection{Análise e discussão dos resultados}

Para que possamos concretizar o objetivo de pesquisa, apresentamos, primeiramente, no Quadro 1, os enunciados que fizeram parte da análise: os depoimentos de duas associadas da AAMA.

\section{Quadro 1. Entrevista com associadas}

QUESTÃo 7: 0 que representa a AAMA em sua vida e o que significa trabalhar em equipe para você?

Associada 1: Como é o primeiro trabalho que eu faço fora de casa, nunca catei, só trabalhei aqui, eu me adaptei. Aqui não importa se a gente é grande ou pequena, porque somos todas "pequenas". Uma ajuda a outra. Todas ajudam se não ajudam a gente faz reunião.

Que nem hoje que a tesoureira faltou de novo, a presidente fala com ela, mas ela não gosta, disse que está trabalhando aqui porque o coordenador pediu, porque ela não precisa. Mas ela não sai. A presidente falou com ela e ela foi estúpida, respondeu mal. Ninguém precisa ouvir desaforo.

Associada 2: Trabalhar em grupo é muito difícil, tem muita fofoca, brigas. Pra mim trabalhar aqui é muito bom, aprendo muitas coisas. Eu não sou obrigada, que nem nos outros trabalhos a cumprir um horário, quando não posso vir, eu aviso. Eu aprendi a trabalhar aqui perguntando as coisas pras outras. Aqui a gente ouve muitas coisas e tem que guardar. Acho que eu faço um bom serviço.

Fonte: entrevistas realizadas.

Selecionamos esta questão - O que representa a AAMA em sua vida e o que significa trabalhar em equipe para você? - porque nossa análise pauta-se na modalidade "falar sobre o trabalho" (NOUROUDINE, 2002) e, a partir dessa seleção, descrevemos e analisamos a(s) cenografia(s) e o ethos discursivo que se constroem das falas das associadas e do coordenador da AAMA, bem como dos documentos - Estatuto e Regimento Interno que regem a instituição.

Sob a perspectiva ergológica, as marcas que identificam a fala da Associada 1 permitem identificar o que Schwartz (2010c, p. 139) observa sobre a linguagem na atividade do trabalho: "seja qual for a atividade [...], o 
corpo está sempre presente; trata-se de algo de muito profundo e que faz parte das habilidades e dos saber-fazer, se podemos assim dizer; o corpo se adestra sem que se possa dizer exatamente como."

Por meio dos sinais evidenciados na fala da Associada 1, é possível visualizar a cena de um sujeito que se inscreve num ambiente, digamos, provisório de trabalho. Não há qualquer perspectiva ou identificação com a atividade, visto que, conforme o depoimento, algumas modalizações imprimem uma situação confortável: "nunca catei”, "só trabalhei aqui", dessa forma "eu me adaptei".

Nas passagens "ela não gosta", "ela não precisa", "ela não sai", observa-se o recurso da negação. Conforme Maingueneau (1997, p. 80), "a negação pode igualmente ser objeto de uma análise polifônica. Na realidade, é antiga a ideia de que é preciso distinguir, em um enunciado negativo, duas proposições, a saber, uma proposição primeira e uma outra que a nega".

Segundo as coordenadas espaço-temporais, a atualização do discurso mediante as marcas verbais no presente organiza o tempo para a instância enunciativa. Desse modo, o plano embreado remete a uma cena que valida a enunciação. É o caso das marcas linguísticas "a gente é", "somos", "todas ajudam", "a presidente fala", "está trabalhando". Assim, à medida que o discurso avança, o enunciador esforça-se para validar a imagem de que trabalhar na AAMA implica "ser pequena", "ouvir o coordenador", "trabalhar em grupo", necessariamente. Especialmente sobre essa última, Schwartz (2010b, p. 141) defende que "As competências para viver - ou as competências em geral - não são somente 'a capacidade para fazer isso'. Trata-se, antes, do reconhecimento de que você é permanentemente uma 'pessoa"'. Nesse particular, trabalhar envolve o contato com o outro, sobremaneira com o outro diferente e, por isso, as condições que circunscrevem o meio laboral sempre se transformam. É o que Schwartz (2010b) denomina como "dramática", porque "jamais se trabalha totalmente sozinho, mesmo quando se tem essa impressão, porque os outros estão lá através da preparação do trabalho, da prescrição, da avaliação" (SCHWARTZ, 2010b, p. 191-192).

É perceptível essa dramática nas falas das duas associadas em estudo. Quando a Associada 2 afirma que "Trabalhar em grupo é muito difícil, tem muita fofoca, brigas", deixa-se transparecer uma cena de conflito. Conflito esse absolutamente aceitável do ponto de vista da atividade, pois "a partir do momento em que há uso e não simplesmente execução, o uso encontra os outros" (SCHWARTZ, 2010b, p. 192).

Sob o viés enunciativo, a partir dos depoimentos das duas associadas, a movimentação dos planos discursivos possibilita a construção de uma cena comum que se caracteriza, principalmente, pela relutância em relação ao outro - "ela foi estúpida", "ninguém precisa ouvir desaforo"-, pelo conformismo - "somos todas pequenas", e pela submissão - "o coordenador pediu", "a gente ouve muitas coisas e tem que guardar." Como desdobramento dos planos constitutivos da semântica global, a cenografia "supõe uma certa situação de enunciação que, na realidade, vai sendo validada progressivamente por intermédio da própria enunciação. [...] a cenografia é ao mesmo tempo a fonte do discurso e aquilo que ele engendra; ela legitima um enunciado que, por sua vez, deve legitimá-la [...]" (MAINGUENEAU, 2011a, p. 87).

Essa realidade coletiva que perpassa o ambiente de trabalho é observada por meio das categorias de pessoa. O pronome possessivo "nosso" - relacionado ao pronome nós e transposto na marca coloquial "a gente" - demarca a presença clara do enunciador. Benveniste (2006) explica que o nós não corresponde à multiplicação do eu; o pronome nós implica um sujeito coletivo. Maingueneau (2011a, p. 127), a partir da concepção benvenistiana desse pronome, assinala que "no nós, a predominância do 'eu' é muito forte, a ponto de, em certas condições, este plural poder passar pelo singular (cf. o 'nós' de majestade ou o 'nós' pelo qual se designa o autor de um livro)".

A experiência coletiva do trabalho orientada pelas coordenadas de pessoalidade e relacionada aos planos constitutivos do discurso denuncia um ethos de submissão, de fragilidade, ainda que, timidamente, as associadas demonstrem certo gosto pelo trabalho na AAMA.

Seguindo com essa análise, vislumbramos outra experiência da atividade: a do coordenador da AAMA.

\section{Quadro 2. Entrevista com o Coordenador}

QUESTÃo 7: Qual é a visão de sua participação na AAMA pela sociedade local, o bairro, e como a sociedade em geral percebe a AAMA no seu ponto de vista? Como você a percebe e como você se percebe nela?

As pessoas sabem que eu não faço parte daquela comunidade... Tu não sabe a pobreza que é aquilo, alguns não têm nem comida. As pessoas não me tratam de igual, é como se eu fosse mais que elas, elas esperam respostas de mim, esperam que eu resolva as coisas. [...] Eu gosto de ir lá na AAMA, mas acho que faço um serviço lento e que não vai ter grandes resultados a curto prazo. O pessoal do Projeto diz que eu tenho que mandar mais, mas eu quero construir, quero que elas construam o conhecimento. Incentivo com perguntas, questionamentos, tento fazer elas pensarem, mas elas querem que eu resolva tudo por elas, me telefonam toda hora.

Fonte: entrevista realizada.

Ante o depoimento do coordenador da AAMA, percebemos, por meio das marcas que constituem seu discurso, uma cenografia que vai de encontro às falas das associadas. Enquanto estas direcionam seu posicionamento sobre o trabalho para uma compreensão pautada pela submissão e prescrição de normas advindas de uma figura superior, este espera que as colaboradoras reajam no sentido de também fazerem parte como 
protagonistas da atividade. A cena validada construída no mundo do trabalho é a de que há, naturalmente, uma hierarquia a ser cumprida. A desconstrução dessa ordem automaticamente gera o que Schwartz (2010b) chama de dramática.

O discurso do coordenador aponta para o entendimento de que, em situações de trabalho, as arbitragens passam pelas movimentações do corpo - a subjetividade. De acordo com Schwartz (2010b, p. 196), muito da inteligência do corpo é resultado "de nossa própria história, de um 'adestramento' que pode ser cultural, mas que em seguida passa na inconsciência, eu diria feliz, do próprio corpo." A movimentação desse corpo carrega consigo uma série de valores e que são manifestados pelos sujeitos no ambiente laboral.

Quando o coordenador aponta que "as pessoas não me tratam de igual", "é como se eu fosse mais que elas", "esperam respostas de mim", "esperam que eu resolva as coisas", "que eu tenho que mandar mais", "elas querem que eu resolva tudo", a cenografia enunciativa revela um ethos de total dependência das trabalhadoras em relação à figura do coordenador, imagem esta que resgata forte vinculação ao "mundo ético", aos "estereótipos" (MAINGUENEAU, 2008b) que antecipam a cena do trabalho no molde taylorista.

No que diz respeito às características da enunciação linguística (MAINGUENEAU, 2011a), as coordenadas actanciais apontam para o plano embreado e o não embreado. O eu (coordenador) se apropria da língua para falar de uma terceira pessoa, elas (as colaboradoras). Os sinais que revelam o plano não embreado criam um sentido de distância em relação às mulheres trabalhadoras e, sobretudo, acerca do coordenador como alguém que seria partícipe da atividade. Assim, semas como "aquilo", "as pessoas", "alguns" lembram a noção inicial para o constructo da cenografia. Conforme Maingueneau (1997, p. 42), a dêixis é somente "um primeiro acesso à cenografia".

E nesse primeiro acesso, a instauração da subjetividade da linguagem e a tensão entre o $e u$ indicam, além da presença do homem na língua, a tensão entre o uso de si por si e o uso de si pelo outro. Há um confronto de cenas e, consequentemente, do ethos presentes nas falas das associadas e do coordenador. Segundo Schwartz (2010b, p. 197), "nós trabalhamos nosso corpo, nós o trabalhamos permanentemente pela nossa experiência de vida - e portanto por nossas paixões, por nossos desejos, por nossas experiências." É nesse trabalhar o corpo que verificamos o embate entre cenas que se constroem de acordo com universos distintos: de um lado, um indivíduo moldado pela necessidade de um trabalho coercitivo pelas trabalhadoras -, por outro lado, a iniciativa do coordenador em inscrever a participação desses sujeitos e, além disso, fazer com que as mulheres se percebam como seres singulares na atividade.

Notamos que a linguagem sobre o trabalho - tanto do coordenador quanto das trabalhadoras - coaduna em um aspecto: o gosto pelo ambiente. É perceptível que a AAMA proporciona, segundo os depoimentos, um espaço de aprendizado. Contudo, a partir das práticas linguageiras, identificamos diferentes cenografias e ethos que configuram distintos saberes e usos de si e pelos outros na experiência da atividade. Enquanto o coordenador, na figura de autoridade, espera que as colaboradoras tomem iniciativa ante o trabalho, estas esperam - conforme o sistema taylorista - atitudes prescritivas de um indivíduo superior a elas: "porque somos todas pequenas".

Desse modo, o próprio discurso atribui um corpo ao seu enunciador; este, por sua vez, exerce a função "de fiador - de uma fonte legitimante - permite ao destinatário construir uma representação dinâmica dele" (CHARAUDEAU; MAINGUENEAU, 2008, p. 272). A noção de "fiador" mantém estreita relação com termos como argumentação, autoridade, incorporação. Isso porque o fiador é uma figura representativa construída pelo leitor/coenunciador a partir dos indícios deixados pelo enunciador. O fiador é "investido de um caráter e de uma corporalidade, cujo grau de precisão varia conforme os textos" (MAINGUENEAU, 2008b, p. 72).

Como o enunciador não é apenas um transmissor de ideias, da mesma forma, o destinatário também não se limita a "consumir" essas ideias. A incorporação é uma espécie de enlaçamento que, em se tratando de análise de discurso, ambos assimilam um modo de ser e de dizer. É essa relação que possibilita a eficácia do discurso.

O modo de dizer e o modo de ser, nas palavras das colaboradoras, denunciam certa imaturidade em relação às variáveis presentes no ambiente de trabalho, ou seja, consoante Schwartz (2010c, p. 141), "às competências para viver", ao reconhecimento de que há sempre um envolvimento com indivíduos diferentes, "com valores que se contradizem mais ou menos e cujo resultado nunca é predeterminado".

Como última análise, apresentamos dois excertos que integram os documentos da AAMA: O Estatuto Social e o Regimento Interno.

Quadro 3. Estatuto Social e Regimento Interno da AAMA

1. Estatuto Social: Elevar coletivamente a autoestima, a solidariedade, a valorização do ser humano, a união, o diálogo, incluindo as pessoas através das atividades desenvolvidas.

2. Regimento Interno: Cumprir com o Estatuto Social e o Regimento Interno da AAMA.

Fonte: 1. Art. 2ํㅡㄹ alínea "d" do Estatuto; 2. Art. 10, inciso II, alínea "b". 
Em razão de a atividade ser demasiado complexa, a ergologia, segundo Trinquet (2010, p.94), "permitiria ao trabalho humano encontrar sua verdadeira razão de ser, fundamental e ontológica, que é favorecer o desenvolvimento de cada indivíduo, tanto no plano humano quanto econômico e social".

Discursivamente, as cenografias que se depreendem das passagens do Estatuto Social e do Regimento Interno tematizam a preocupação da instituição para com os valores dos indivíduos que dela participam, pois figurativizam um espaço de cooperação. Além disso, o uso de si pelos outros parece ser, além de prioridade, uma obrigação, já que os sujeitos atuantes devem "cumprir com o Estatuto Social e o Regimento Interno da AAMA". Depreende-se, portanto, desses documentos, o ethos coletivo; o saberfazer é indissociável do contato com o outro, já que as "diferentes atividades supõem a cooperação entre os atores" (SOUZA-E-SILVA, 2002, p. 67).

Constatamos que o ethos da AAMA é a de uma instituição democrática no sentido de singularizar a atividade das pessoas envolvidas. Além disso, o uso de si e o direito à voz são propriedades inerentes que configuram o objetivo da Associação: promover o desenvolvimento integral do ser humano e inseri-lo social e culturalmente.

\section{Considerações finais}

Ao propormos uma interface entre uma teoria linguístico-discursiva (Dominique Maingueneau) e a ergologia (Yves Schwartz), objetivamos analisar a cenografia e o ethos construídos a partir de dizeres (falas) de pessoas que integram a AAMA, especificamente, as mulheres associadas, o coordenador e, também, os fragmentos dos documentos Estatuto Social e do Regimento Interno.

Como problema de pesquisa, partimos da seguinte questão: a cenografia e o ethos discursivo possibilitam revelar uma representação sociocultural da associação construída pelos indivíduos que dela participam? A análise permitiu-nos comprovar a hipótese de que essas categorias linguístico-discursivas viabilizam identificar e analisar os saberes sobre a atividade expressa pelos indivíduos em situações de trabalho. A confirmação da hipótese e a concretização do objetivo de estudo foram possíveis por meio da elaboração do roteiro metodológico, o qual contemplou em sua organização a funcionalidade de conceitos advindos da teoria linguístico-discursiva (MAINGUENEAU, 1997, 2008a, 2008b, 2008c, 2008d, 2010, 2011a, 2011b) e da ergologia (SCHWARTZ, 2010; TRINQUET, 2010; NOUROUDINE, 2002).

Como analisamos discursos manifestados em um ambiente de interação social, registramos o movimento de cenografias variadas e, consequentemente, de distintos ethé. De acordo com Trinquet (2010, p. 111), "quando se interessa em estudar o trabalho, é preciso reconhecer que a atividade de trabalho é sempre expressão de uma relação social. Que ela é condicionada por essa relação social e, sobretudo, pelo estado de forças sociais presentes".

Foi nessa tensão que observamos divergências quanto à imagem discursiva sobre a atividade. Enquanto as associadas manifestaram a dificuldade, sobretudo, de trabalhar em grupo, além de se verem como indivíduos inferiores ante o coordenador, este prima, em seu discurso, pela união e autonomia das mulheres, já que ele deixa transparecer a preocupação em promover a integração do grupo. Essa mesma imagem é, inclusive, registrada nos documentos da Associação.

Embora tanto o regimento quanto o estatuto da AAMA registrem o diálogo como essência de uma organização, as associadas deixam transparecer - pela análise da cenografia e do ethos - o modo canônico de organização do trabalho. Elas ainda mantêm o sistema taylorista de trabalho, uma vez que se veem apenas como funcionárias, e não como sócias. Assim, a imagem evidenciada no discurso dessas pessoas mostra a atividade como um processo de execução, em que a obrigação do coordenador é prescrever e a do trabalhador é a de executar e executar bem. É no uso de si e o uso de si pelos outros que reside a complexidade da atividade.

\section{Referências}

BENVENISTE, Émile (1970). O aparelho formal da enunciação. In: Problemas de linguística geral II. 2. ed. Tradução Eduardo Guimarães et al. São Paulo: Pontes, 2006. p. 81-90.

CHARAUDEAU, Patrick; MAINGUENEAU, Dominique. Dicionário de Análise do Discurso. Coordenação da tradução Fabiana Komesu. 2.ed. São Paulo: Contexto, 2008.

DI FANTI, Maria da Glória Corrêa di Fanti. Linguagem e trabalho: diálogo entre a translinguística e a ergologia. Desenredo, Passo Fundo, v. 8, n. 1, p. 309-329, jan.-jun. 2012.

FAÏTA, Daniel. Análise das práticas linguageiras e situação de trabalho: uma renovação metodológica imposta pelo objeto. In: SOUZA-E-SILVA, M.C.P.; FAÏTA, D. (Org.). Linguagem e trabalho: construção de objetos de análise no Brasil e na França. Tradução Inês Polegatto, Décio Rocha. São Paulo: Cortez, 2002. p. 45-60.

FREITAS, Ernani Cesar de. Cultura, linguagem e trabalho: comunicação e discurso nas organizações. Desenredo, v. 7, n. 1, p. 104-126, jan.-jun. 2011.

FREITAS, Ernani Cesar de; CHIARADIA, Itatiane. Práticas discursivas em contextos sociais: linguagem e trabalho em uma associação de catadores de materiais recicláveis. Moara, n.38, p. 92-112, jul./dez. 2012. Disponível em: <http://www. periodicos.ufpa.br/index.php/moara/issue/view/Revista\%20 Moara/showToc>. Acesso em: 27 out. 2013. 
MAINGUENEAU, Dominique (1987). Novas tendências em análise do discurso. 3. ed. Tradução Freda Indursky. Campinas: Pontes; Ed. da Unicamp, 1997.

MAINGUENEAU, Dominique. (1984). Gênese dos discursos. Tradução Sírio Possenti. São Paulo: Parábola Editorial, 2008a.

MAINGUENEAU, Dominique. (2005). Ethos, cenografia, incorporação. In: AMOSSY, Ruth (Org.). Imagens de si no discurso: a construção do ethos. Tradução Dilson Ferreira da Cruz, Fabiana Komesu e Sírio Possenti. São Paulo: Contexto, 2008b. p. 69-92.

MAINGUENEAU, Dominique. (2006). Cenas da enunciação. São Paulo: Parábola Editorial, 2008c.

MAINGUENEAU, Dominique . Discurso e análise do discurso. In: SIGNORINI, Inês (Org.). [Re]discutir texto, gênero e discurso. São Paulo: Parábola Editorial, 2008d. p. 135-156.

MAINGUENEAU, Dominique. Doze conceitos em análise do discurso. Tradução Adail Sobral et al. São Paulo: Parábola Editorial, 2010.

MAINGUENEAU, Dominique. (2000). Análise de textos de comunicação. 6. ed. Tradução Cecília P. de Souza-e-Silva, Décio Rocha. São Paulo: Cortez, 2011a.

MAINGUENEAU, Dominique. A propósito do ethos. In: MOTTA, Ana Raquel; SALGADO, Luciana (Org.). Ethos discursivo. 2. ed. São Paulo: Contexto, 2011b. p. 11-30.

MUSSALIM, Fernanda. Uma abordagem discursiva sobre as relações entre ethos e estilo. In: MOTTA, Ana Raquel; SALGADO, Luciana (Org.). Ethos discursivo. 2. ed. São Paulo: Contexto, 2011. p. 70-81.

NOUROUDINE, Abdallah. A linguagem: dispositivo revelador da complexidade do trabalho. In: SOUZA-E-SILVA, M.C.P.; FAÏTA, D. (Org.). Linguagem e trabalho: construção de objetos de análise no Brasil e na França. Tradução Inês Polegatto, Décio Rocha. São Paulo: Cortez, 2002. p. 17-30.

POSSENTI, Sírio. Discurso, estilo e subjetividade. São Paulo: Martins Fontes, 1993. (Texto e Linguagem).

POSSENTI, Sírio. Ethos e corporalidade em textos de humor. In: MOTTA, Ana Raquel; SALGADO, Luciana (Org.). Ethos discursivo. São Paulo: Contexto, 2011. p. 149-156.
SCHWARTZ, Yves. Trabalho e ergologia. In: SCHWARTZ, Yves; DURRIVE, Louis. (Org.). Trabalho e ergologia: conversas sobre a atividade humana. Coord. da tradução e revisão técnica: Jussara Brito e Milton Athayde. 2. ed. Niterói: Ed. da UFF, 2010a. p. 25-46.

SCHWARTZ, Yves. Trabalho e uso de si. In: SCHWARTZ, Yves. (Org.). Trabalho e ergologia: conversas sobre a atividade humana. Coord. da tradução e revisão técnica: Jussara Brito e Milton Athayde. 2. ed. Niterói: Ed. da UFF, 2010 b. p. 187-204.

SCHWARTZ, Yves. A linguagem em trabalho. In: SCHWARTZ, Yves; DURRIVE, Louis. Trabalho e ergologia: conversas sobre a atividade humana. Coord. da tradução e revisão técnica: Jussara Brito e Milton Athayde. 2.ed. Niterói: Ed. da UFF, 2010c. p. 131-148.

SILVA, Edvania Gomes da. Os (Des)encontros da fé: análise interdiscursiva de dois movimentos da Igreja Católica. 2006. 293 f. Tese (Doutorado em Linguística) -Universidade Estadual de Campinas, Campinas, 2006.

SOUZA-E-SILVA, Maria Cecília. A dimensão linguageira em situações de trabalho. In: SOUZA-E-SILVA, Maria Cecília P.; FAÏTA, Daniel (Org.). Linguagem e trabalho: construção de objetos de análise no Brasil e na França. Tradução Inês Polegatto e Décio Rocha. São Paulo: Cortez, 2002. p. 61-76.

TEIXEIRA, Marlene. O ato enunciativo e a instauração da experiência de trabalho de profissionais de enfermagem. Moara, n. 38, 37-53, jul.-dez. 2012. Disponível em: <http://www. periodicos.ufpa.br/index.php/moara/issue/view/Revista $\% 20$ Moara/showToc>. Acesso em: 23 out. 2013.

TRINQUET, Pierre. Trabalho e educação: o método ergológico. Revista HISTEDBR On-line, Campinas, SP, n. esp., p. 93-113, ago. 2010. Disponível em: $<$ http://www.histedbr.fae.unicamp. br/revista/edicoes/38e/art07_38e.pdf $>$. Acesso em: 27 out. 2013.

Recebido: 13 de novembro de 2013

Aprovado: 05 de fevereiro de 2014

Contato: ecesar@upf.br; deborafacin@upf.br deborafacin@upf.br 